\title{
Empreendedorismo feminino: um estudo fenomenológico
}

\section{RESUMO}

O crescente aumento no número de mulheres empreendedoras em diversos ramos de negócios, as alterações de seu papel na sociedade e suas conquistas foram os fatores que nortearam o desenvolvimento destetrabalho, cujo objetivoéapresentaro perfil dasempreendedoras entrevistadas, suas características pessoais, como ocorreu o desenvolvimento de seu empreendimento, bem como a sua visão atual e futura sobre os seus respectivos negócios. A pesquisa foi desenvolvida com base no método fenomenológico-interpretativista, que se revelou adequado para identificar não somente as características explícitas das entrevistadas, mas também aspectos da subjetividade, que demonstram a existência nelas de um perfil empreendedor. Os resultados mostraram que estão presentes no perfil delas, características como persistência, busca de oportunidades, iniciativa, comprometimento, persuasão e autoconfiança, as quais as definem como mulheres empreendedoras.

Palavras-chave: Empreendedorismo feminino. Perfil empreendedor. Análise fenomenológica.

Suely da Silva Carreira sscarreira@gmail.com Doutoranda - Universidade Federal de Santa Catarina - UFSC Ana Bencciveni Franzoni anafranzoni@gmail.com Doutoranda - Universidade Federal de Santa Catarina - UFSC Aulina Judith Folle Esper aulina.esper@gmail.com Mestranda - Universidade Federal de Santa Catarina - UFSC Daniela Chagas Pacheco Mestranda - Universidade Federal de Santa Catarina - UFSC

Fabiana Bohm Gramkow fbgramkow@hotmail.com Doutoranda - Universidade Federal de Santa Catarina - UFSC

Manoel Francisco Carreira mfcarreira@uem.br 


\section{INTRODUÇÃO}

Empreendedorismo certamente é um dos temas centrais da Sociedade do Conhecimento. Falar em Sociedade do Conhecimento, conforme Evers (2001), significa dizer que, na atualidade, o conhecimento, acima do capital e da força de trabalho, é o principal fator de produção, além de ser um elemento que perpassa não somente a cadeia produtiva, mas também a coletividade.

Ter o conhecimento como elemento-chave nessa sociedade é levar em consideração que os processos de produção, disseminação e utilização do conhecimento perpassam a dinâmica das organizações e do convívio social. Nesse sentido, inovação é um imperativo, e não somente a inovação em produtos e serviços, desenvolvida nos departamentos de Pesquisa e Desenvolvimento (P\&D) das organizações, mas também o desenvolvimento de negócios inovadores, seja em novas áreas de mercado, seja nos segmentos já consolidados.

Tendo em vista esse contexto e o tema aqui abordado, cujo foco são as mulheres empreendedoras, o presente trabalho constitui-se em uma pesquisa qualitativa, caracterizada pela entrevista com doze mulheres empreendedoras, visando apresentar o perfil delas, suas características pessoais, como foi o desenvolvimento de seu empreendimento, assim como a sua visão atual e futura sobre os seus respectivos negócios. Desse modo, foram entrevistadas mulheres empreendedoras com atuação em diversos ramos de negócio.

O artigo, na sequência, é dividido em quatro partes. A primeira apresenta a fundamentação teórica a respeito das categorias empreendedorismo e empreendedorismo feminino; a segunda trata da metodologia adotada; na terceira, são apresentados os resultados e discussões acerca das entrevistas com mulheres empreendedoras, e, finalmente, a quarta traz as considerações finais.

\section{FUNDAMENTAÇÃO TEÓRICA}

Para sustentar e fundamentar teoricamente os objetivos deste trabalho, que é investigar o perfil empreendedor das mulheres entrevistadas, em um primeiro momento será mostrado um panorama geral das noções de empreendedorismo (masculino e feminino), subsídios necessários para uma melhor interpretação dos dados obtidos.

\subsection{Empreendedorismo}

A noção de empreendedorismo considera aquelas pessoas que geram ou aproveitam oportunidades na sociedade e, a partir disso, desenvolvem uma atividade econômica organizada, criando valor para si e para a sociedade, razão pela qual Rosa, Souza e Loch (2011) entendem que essas pessoas são responsáveis pelo desenvolvimento pessoal e da sociedade, chamando a atenção pelos resultados que elas alcançam.

Schumpeter (1997) vê no empreendedor uma das pessoas-chave de seu sistema econômico, visto que este é quem porta consigo próprio o processo de inovação, que permite revoluções nas estruturas econômicas e sociais, mediante o processo chamado pelo autor de "destruição criadora" a substituição de antigos produtos (bens e serviços) por novos.

Como se nota, tratar a respeito de empreendedorismo é tratar sobre a figura do empreendedor e sobre os resultados que este traz para a sociedade, por meio do seu empreendimento. Zampier e Takahashi (2011) salientam que o empreendedor é marcado por características pessoais e por ações empreendedoras, razão pela qual se criou o conhecimento de competência empreendedora. Referida competência envolve conhecimentos, habilidades e atitudes que o empreendedor possui e que geram os resultados trazidos por ele à sociedade.

Cooley (1990) foi um dos principais autores a trazer um modelo que identifica as competências do empreendedor. O autor apresenta dez características como representativas de um empreendedor, a saber: (1) estabelecimento de metas; (2) planejamento e monitoramento sistemático; (3) persistência; (4) comprometimento; (5) busca de informações; (6) busca de oportunidades e iniciativa; (7) exigência de qualidade e eficiência; (8) busca de riscos calculados; (9) persuasão e rede de contatos; (10) independência e autoconfiança.

Cooley (1990) entende como estabelecimento de metas a definição dos objetivos que são desafiantes e que têm significado pessoal. Essas metas e objetivos têm visão de longo prazo, clara e específica, mas também há metas de curto prazo mensuráveis. Por outro lado, não basta apenas fixar metas, é preciso realizá-las. Assim, em seguida, há o planejamento e monitoramento sistemático, dividindo-se tarefas, revisando-se os planos com base nos resultados obtidos e mantendo-se o controle financeiro, utilizando-o como base para a tomada de decisão. 
Para o empreendedor é de suma importância gerir de forma correta sua organização; mas, muitas vezes, a figura do empreendedor é confundida com a do gestor, nem todo empreendedor é um gestor. Assim, outros elementos complementam a figura do empreendedor, como a persistência, ou seja, o fato de um obstáculo significativo não demover o empreendedor de seu objetivo. $O$ empreendedor age repetidamente ou muda de estratégia, a fim de enfrentar desafios e superar obstáculos, mesmo que, para tanto, seja necessário o sacrifício pessoal.

Cooley (1990) esclarece que o empreendedor é também comprometido, pois atribui a si mesmo e ao seu comportamento as causas de seus sucessos ou fracassos e assume responsabilidade pessoal pelos resultados obtidos. Ele é uma pessoa que colabora com os empregados e coloca-se no lugar deles, se necessário, para terminar uma tarefa, além de se esforçar para manter clientes satisfeitos em uma relação duradoura.

Outras características somam-se a essa figura, como a busca de informações, a preocupação em conhecer seus clientes, fornecedores e concorrentes, a investigação de como dominar a técnica de fabricação de um produto ou fornecimento de determinado serviço, além de consulta a especialistas para obter assessoria técnica ou comercial, sem confiar-lhes a definição final do formato do negócio.

O empreendedor busca oportunidades e tem iniciativa, e, mais do que isso, como diz Cooley (1990), é propriamente uma pessoa capaz de ver tais oportunidades de negócios. Onde as pessoas em geral veem uma matéria consolidada e indiscutível, ele vê uma oportunidade de melhoria, ou de desenvolvimento de algo completamente novo. Reflexo dessa característica é o fato de ele desenvolver suas ações antes de ser solicitado ou forçado pelas circunstâncias, e de agir para expandir o negócio e aproveitar oportunidades fora do comum para começar um negócio novo.

O empreendedor é também uma pessoa exigente, que busca a qualidade e a eficiência em tudo o que realiza, procurando atuar de forma ágil e com baixo custo. Além de procurar satisfazer ou exceder aos padrões de excelência, também desenvolve ou utiliza procedimentos para assegurar que o trabalho seja concluído a tempo, atendendo aos padrões combinados.

Inovar significa ousar; porém, como observa Cooley (1990), o empreendedor não é um ser irresponsável, ele procura correr riscos calculados, por mais altos que estes possam ser, avaliando alternativas e agindo na busca pela minimização desses riscos e mantendo o controle dos resultados.

A realização de uma ideia ou projeto não é uma atividade solitária, depende de pessoas comprometidas. Assim, o empreendedor é alguém que sabe ser persuasivo e constrói uma rede de contatos valiosa, que lhe permite utilizar pessoas-chave como agentes para o alcance de seus próprios objetivos. Ademais, o empreendedor tem de ser alguém que estabelece relações comerciais.

Finalmente, Cooley (1990) identifica nos verdadeiros empreendedores a independência e a autoconfiança, qualidades que se refletem na busca de autonomia em relação a normas e controles de outras pessoas e no fato de manterem seus pontos de vista mesmo diante da oposição de outros ou de resultados desanimadores, além de terem confiança em si próprios perante um desafio.

Figura 1 - Características empreendedoras

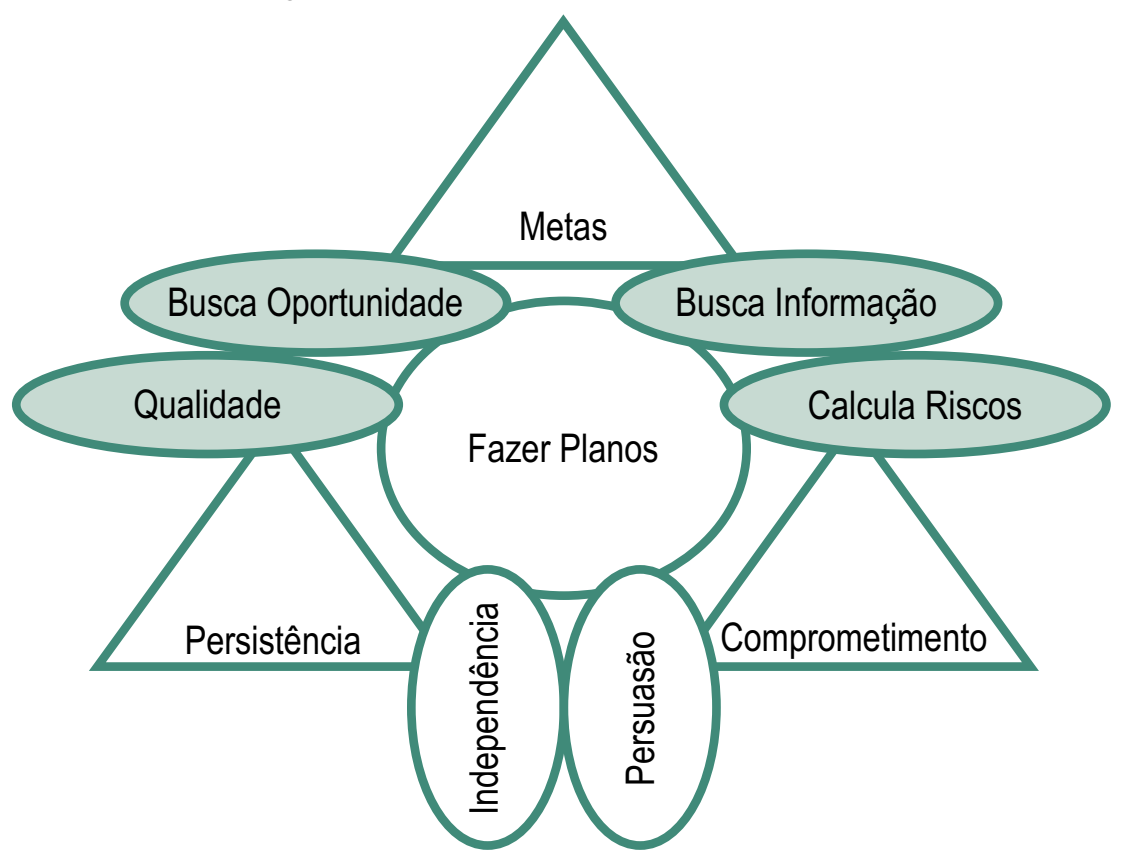

Fonte: Lapolli e Franzoni (2012, p. 123) 
A Figura 1 sintetiza a visão das características do empreendedor e apresenta as inter-relações entre elas.

\subsection{Empreendedorismo feminino}

A sociedade contemporânea é muito mais aberta à figura da mulher empreendedora, se comparada às configurações sociais anteriores, embora em determinadas situações a posição de referência feminina nos negócios ainda represente um paradigma a ser superado. Independentemente de visão ideológica e política, o fato de, em 2010, a população brasileira haver elegido uma mulher como Presidente da República representa bem a aceitabilidade da mulher, não somente no mercado de trabalho, mas também na posição de empreendedora e gestora de grandes negócios.

O número de mulheres empreendedoras tem crescido três vezes mais, em comparação com a taxa de crescimento das empresas globais dos Estados Unidos da América, de acordo com o Centro de Pesquisa de Mulheres de Negócios desse país, conforme ressalta Dickson (2010). Na pesquisa, observa-se o aumento do número de jovens empreendedoras que iniciam suas empresas ainda na faculdade, principalmente em universidades com programas voltados ao empreendedorismo.

Quanto ao Brasil, dados de 2012 do Relatório da Global Entrepeneurship Monitor (GEM) indicam que a taxa de empreendedorismo feminino inicial é de $14,7 \%$ da população adulta, o que coloca o Brasil na $15^{\text {a }}$ posição entre 67 países pesquisados. Comparando-se a razão entre o número de empreendedores e empreendedoras no Brasil, há o valor de 1,1. A relação entre homens e mulheres empreendedoras é muito próxima da igualdade e, nesse quesito, o Brasil é superado apenas por nove países. Considerando-se, finalmente, as empreendedoras estabelecidas, ou seja, as que conduzem negócios já existentes, o Brasil ocupa o $6^{\circ}$ lugar entre os 67 países (GLOBAL ENTREPENEURSHIP MONITOR, 2012), com 13,1\% da população adulta.

Nessa mesma pesquisa, a taxa de empreendedorismo inicial feminino na região Sul superou a média brasileira, perfazendo o total de $15,3 \%$, sendo a razão masculino/feminino de 1 , mais proporcional que a do Brasil. Com relação ao empreendedorismo estabelecido, o resultado é levemente menor que a média nacional, com 13\% de taxa de empreendedorismo feminino e 1,6 de razão entre os gêneros. A Tabela 1 mostra a comparação entre os índices citados.

Tabela 1 - Índices de empreendedorismo por gênero feminino no Brasil e na região Sul

\begin{tabular}{l|c|c}
\hline Parâmetros & Índice nacional & İndice da região Sul \\
\hline $\begin{array}{l}\text { Empreendedorismo feminino } \\
\begin{array}{l}\text { Relação entre empreendedorismo } \\
\text { masculino e feminino }\end{array}\end{array}$ & $14,7 \%$ & $15,3 \%$ \\
\hline
\end{tabular}

Fonte: GEM (2012, p. 58)

Como se percebe, ainda há diferenças entre os resultados dos homens e os das mulheres, muito embora essas diferenças tenham se reduzido ao longo dos últimos anos. Aliás, pesquisas do Conselho Empresarial da Mulher (WEC), nos Estados Unidos, demonstram que está crescendo a participação feminina em negócios ligados tradicionalmente ao gênero masculino, como, por exemplo, varejo, indústria, construção civil e agronegócio (DICKSON, 2010).

Esse fato está relacionado à crescente capacitação das mulheres nessas profissões, em razão do rendimento que esses negócios apresentam. Uma publicação do Sebrae (2011) também mostra crescimento da participação empreendedora feminina em diversas áreas, inclusive na de transporte coletivo. Observa-se que a diversidade da atuação da mulher no mercado de trabalho e a sua competência para gerir empresas têm Ihe proporcionado a oportunidade de aventurar-se no mundo dos negócios.

Gomes (2006) esclarece que, conquanto as mulheres ainda encontrem dificuldades para chegar aos níveis superiores de gestão corporativa, elas encontraram uma maneira de contornar as dificuldades e abrir suas próprias empresas. Uma das dificuldades enfrentadas pelos empreendedores iniciantes (ambos os gêneros) é a falta de crédito, pois, em geral, as instituições bancárias priorizam o crédito para gestores com experiência e suporte patrimonial.

Alguns elementos são identificados por Dickson (2010) como característicos do fenômeno das mulheres empreendedoras, por exemplo, as mulheres inicialmente aprenderam a gerir o dinheiro como gerem os seus orçamentos familiares, em que a única maneira de aumentar o dinheiro disponível ou fazer crescer a poupança é ser mais frugal. Assim, muitas cresceram em seus negócios sem empréstimos. Salienta-se, porém, que, apesar de conseguirem ampliar seus negócios, na maioria 
das vezes, sem recorrer a empréstimos, é importante compreender que quando realizado de forma viável pode ser um impulso para o crescimento dos negócios.

O empréstimo serve para financiar equipamentos, promover vendas ou outras necessidades de negócios, como por exemplo, inovação e ampliação. Requerer empréstimo deve ser visto como uma possibilidade para ir de um estágio de negócio para outro. Considerando que o empréstimo é um elemento de risco, Gomes (2006) esclarece que as mulheres empresárias, por serem mais cautelosas, demoram mais para crescer em seus empreendimentos.

Como se verifica, algumas das características citadas por Cooley (1990) não correspondem ao perfil da empreendedora mulher traçado por Gomes (2006), ou seja, Cooley (1990) pensou apenas no empreendedor homem, enquanto Gomes (2006) relata as características do perfil da mulher empreendedora.

Na sequência, são apresentados os procedimentos metodológicos para alcance do objetivo proposto, que é apresentar o perfil empreendedor das mulheres entrevistadas.

\section{PROCEDIMENTOS METODOLÓGICOS}

A pesquisa foi desenvolvida com base no método fenomenológico-interpretativista de Taylor e Bogdan (1997), que se revelou adequado para identificar não somente as características explícitas das entrevistadas, mas também aspectos da subjetividade delas.

Quanto ao instrumento adotado, utilizou-se o roteiro de entrevista, retirado dos livros "Mulheres Empreendedoras" e"Vitrine de Talentos", baseados no modelo de Cooley (1990). A análise dos dados foi realizada pelo método interpretativista de Taylor e Bogdan (1997), o qual consiste em apresentar o foco das questões, bem como as respostas obtidas.

\section{ANÁLISE DOS RESULTADOS}

A seguir, apresenta-se o resultado da aplicação da pesquisa, composta por uma amostra de doze mulheres (três de Blumenau/SC, três de São Paulo/SP, três de Criciúma/SC e três de Maringá/PR). A amostra foi direcionada e intencional, com base no conhecimento prévio dos autores em relação às entrevistadas, que se tratava de mulheres empreendedoras no seu segmento de atuação.

O objetivo da pesquisa é apresentar o perfil das empreendedoras entrevistadas, suas características, como o seu empreendimento desenvolveu-se, bem como a sua visão atual e futura do seu negócio. Para tanto, foram elencados doze quesitos baseados em Cooley (1990): (1) definição de metas, (2) planejamento e monitoramento sistemático, (3) persistência, (4) comprometimento, (5) busca de informações e oportunidades, (6) iniciativa, (7) exigência de qualidade e eficiência, (8) coragem para correr riscos calculados, (9) persuasão, (10) rede de contatos, (11) independência e (12) autoconfiança.

Com base nos quesitos mencionados, foi elaborado o questionário para a entrevista com as empreendedoras; ao final foi indagado sobre a identificação de algum ponto que elas consideravam que justificasse o seu sucesso.

O Quadro 1 apresenta duas colunas, a primeira identifica o foco principal da questão apresentada e a segunda, as principais respostas ao questionamento. Relacionando-se às questões com as respostas, é possível direcionar a análise da pesquisa.

Quadro 1 - Síntese do conteúdo das entrevistas com as empreendedoras

\begin{tabular}{|c|l|}
\hline Foco das questões & \multicolumn{1}{|c|}{ Principais respostas das empreendedoras } \\
\hline \multirow{4}{*}{$\begin{array}{c}\text { Metas/ } \\
\text { Planejamento }\end{array}$} & "ter planejamento para 3 e 5 anos e 2 meses - curto prazo" \\
\cline { 2 - 2 } & "minha meta principal é fazer cada vez melhor o que faço" \\
\cline { 2 - 2 } & "aumentar a equipe para atender à demanda" \\
\cline { 2 - 2 } & "ter uma editora com reconhecimento nacional" \\
\cline { 2 - 2 } & "muitos sonhos - planejo tudo e me dedico até acontecer" \\
\hline \multirow{3}{*}{$\begin{array}{c}\text { Persistência e } \\
\text { Compromisso }\end{array}$} & "todo mundo dizia que daria errado, fiz assim mesmo" \\
\cline { 2 - 2 } & "gosto de tudo organizado" \\
\cline { 2 - 2 } & "uma característica minha é a perseverança" \\
\hline
\end{tabular}




\begin{tabular}{|c|c|}
\hline \multirow{3}{*}{$\begin{array}{l}\text { Busca de Informações/ } \\
\text { Oportunidades }\end{array}$} & $\begin{array}{l}\text { "percebi que o mercado carecia de roupas íntimas femininas com mais qualidade, } \\
\text { conforto e beleza" }\end{array}$ \\
\hline & "fiz pesquisa de mercado e elaborei um plano de negócios" \\
\hline & "a cada dia buscando mais conhecimento" \\
\hline \multirow{7}{*}{ Iniciativa } & "comecei a confeccionar roupas sozinha" \\
\hline & "procurei o Sebrae" \\
\hline & "comecei a vir para a empresa e me inteirar de tudo" \\
\hline & "criei minha própria marca" \\
\hline & "encarei o desafio" \\
\hline & "decidi ter mais tempo para a família" \\
\hline & "cursei uma segunda faculdade" \\
\hline \multirow{6}{*}{$\begin{array}{l}\text { Exigência de qualidade e } \\
\text { eficiência }\end{array}$} & "gosto das coisas organizadas" \\
\hline & "maneira de pedir é uma ordem" \\
\hline & "exijo boa aparência, isso é muito importante" \\
\hline & "todas as funções são delegadas" \\
\hline & "nós queremos o sucesso dos nossos clientes" \\
\hline & "conheço os clientes e conheço a história de cada um" \\
\hline \multirow{4}{*}{$\begin{array}{l}\text { Persuasão e Rede de con- } \\
\text { tatos }\end{array}$} & "minha rede é o próprio cliente" \\
\hline & "trabalho com parcerias, não somos nada sozinhos" \\
\hline & "tenho parcerias" \\
\hline & "algumas pessoas me acompanham desde o início" \\
\hline \multirow{4}{*}{ Correr riscos calculados } & "os investimentos foram com recursos próprios" \\
\hline & "só planejo quando já tenho o dinheiro" \\
\hline & "já fui mais ousada, hoje sou mais pé no chão" \\
\hline & "no início arrisquei muito, hoje sou mais cautelosa" \\
\hline \multirow{5}{*}{$\begin{array}{l}\text { Independência e Autocon- } \\
\text { fiança }\end{array}$} & "quem me socorreu nas dificuldades foi minha avó" \\
\hline & "minha família sempre me apoiou com incentivo" \\
\hline & "família é tudo para qualquer pessoa realizar seus sonhos" \\
\hline & "Devo tudo o que tenho a Deus" \\
\hline & "procurei ter tempo para a família" \\
\hline \multirow{6}{*}{ Sucesso } & "minha marca hoje é um sucesso" \\
\hline & "minha escola começou com oito alunos hoje tenho 2.000 " \\
\hline & "tenho cliente há mais de dezenove anos" \\
\hline & "o sucesso não é só meu, trabalho em equipe" \\
\hline & "é a soma de tudo, as oportunidades aparecem" \\
\hline & "foi construir a sede própria" \\
\hline
\end{tabular}

Fonte: Primária (2014)

As entrevistadas encontram-se na faixa etária dos 40 anos e possuem formação nas áreas de Direito, Jornalismo, Pedagogia, Moda, Psicologia, Administração e Contabilidade.

Com base nas informações coletadas durante as entrevistas, foi possível extrair situações que caracterizam o perfil, permitindo comprovar sua consistência e identificar o perfil e o comportamento empreendedor das participantes.

Nas entrevistas, ficaram evidenciadas iniciativas e atitudes, ou seja, os comportamentos empreendedores. Essas mulheres demonstraram que o alicerce do desenvolvimento de suas atividades é o planejamento de metas e que, quando os objetivos são traçados, existe persistência e comprometimento; elas ressaltaram que se deve acreditar na realização e buscar fazer tudo com muita dedicação e da melhor forma.

Observou-se que a busca de informações é parte do desenvolvimento das empresas em estágio embrionário, que elas trabalham com pesquisa de mercado e o quesito oportunidades é marcante no 
seu perfil, disseram estar atentas "a tudo o que se passava à sua volta" para perceber o que poderiam fazer para ter sua própria empresa.

A iniciativa é uma característica das mais marcantes, pois a trajetória profissional descrita por elas mostrou que precisaram ter comportamentos de atitude para conseguirem chegar onde estão. Muito trabalho, dedicação, inovação e perseverança foram ações e atitudes percebidas. No perfil dessas mulheres, notou-se que o padrão de comportamento é "não desistir nunca".

No quesito"riscos", percebeu-se que elas agem sempre com segurança e relataram ter sido mais ousadas no início, mas atualmente agem com mais cuidado e com menos ansiedade, de forma que as decisões de investimentos só acontecem quando já existe o dinheiro. Atualmente gostam de segurança.

As entrevistadas relataram que normalmente conseguem, em diferentes situações e por diversas razões, induzir e/ou convencer pessoas a fazer algo que queriam e afirmaram que o fazem com criatividade e de diferentes maneiras. As entrevistadas relataram também situações em que vivenciaram grandes dificuldades para alcançar seus objetivos, mas continuaram, perseveraram e superaram os obstáculos de diversas naturezas e origens. Outro fator importante é sentir a satisfação de terem realizado algo significativo em sua vida, tanto do ponto de vista pessoal como do profissional e que contribui para o sucesso de outras pessoas.

A autoconfiança foi uma característica relevante no perfil dessas mulheres. Elas relataram a importância da família para o seu sucesso, e o que se percebeu é que elas possuem muita fé em Deus e consideram isso um fator primordial para o desenvolvimento da autoconfiança.

Com relação ao sucesso, afirmaram que foi o trabalho em equipe: "foi um trabalho de muitas mãos". Para elas, o sucesso é fruto de muito trabalho e dedicação; também consideram que o número de clientes e as aquisições patrimoniais são indicativos de que tudo deu certo.

Ao final da entrevista, foi questionado que sugestões elas dariam para quem deseja abrir uma empresa e a respostas foram as seguintes:

"Faça algo que você goste."

"Conhecimento e estabilidade emocional devem estar juntos, só assim teremos grandes pessoas formadas para a nossa nação."

"Pesquisa de mercado, ter paixão e não perder o foco."

"Você tem que ter um propósito para a comunidade, cada empresa tem o seu papel, tem que ter um diferencial."

"É preciso estar bem consigo, tratar bem o outro e cuidar de si."

As sugestões aqui apresentadas demonstram que, para iniciar um empreendimento, é necessário pesquisar o mercado, fazer o que se gosta, e que toda empresa tem de apresentar um diferencial para que possa ser competitiva no seu mercado de atuação.

Os resultados apresentaram que estão presentes no perfil das entrevistadas características como persistência, busca de oportunidades, iniciativa, comprometimento, persuasão e autoconfiança, o que as define como mulheres empreendedoras. Todas relataram que a busca de seus sonhos sempre foi direcionada pela fé em Deus e que o apoio da família foi um dos fatores que contribuíram para o seu sucesso como empreendedoras.

\section{CONSIDERAÇÕES FINAIS}

O presente trabalho é resultante da análise teórico-prática do fenômeno do empreendedorismo feminino, que vem aumentando e destacando-se. A pesquisa apresentou o perfil, as características pessoais de mulheres empreendedoras, como foi o desenvolvimento do próprio empreendimento, assim como sua visão atual e futura sobre os respectivos negócios. Foram realizadas entrevistas com doze participantes dos estados de São Paulo, Santa Catarina e Paraná, e a análise de seus dados foi comparada ao referencial teórico relacionado.

Depois da análise dos dados obtidos, foi possível constatar que as empreendedoras possuem as seguintes características: persistência e determinação alicerçadas pela coragem e confiança no trabalho que realizam; visão de mercado e de oportunidades com base em pesquisas; intuição e percepção de oportunidades; perseverança nos seus objetivos; mantendo a família e a fé como aliados, apoiadores e até como alicerces. Além disso, estabelecer e cumprir metas estão entre seus maiores pontos fortes, somando-se a eles o planejamento e cumprimento de prazos.

Também merecem destaque iniciativas e atitudes, como a formação e manutenção de uma sólida rede de contatos; no quesito "riscos", preferem agir com segurança e moderação e, como consequência, vivenciam o sucesso, com o resultado traduzido em marcas conhecidas e requisitadas, clientes numerosos, satisfeitos e fidelizados. 
A contribuição resultante da pesquisa para a ciência reside primeiramente na compreensão da correlação entre as características do perfil das mulheres entrevistadas e os sinais distintivos do comportamento empreendedor. Além disso, o estudo permitiu analisar a importância do comportamento empreendedor e do empreendedorismo feminino, podendo-se concluir que o objetivo foi alcançado, ou seja, apresentou o perfil e características pessoais de mulheres empreendedoras. Estas mostraram ter iniciativa e confiança em suas atitudes empreendedoras, o que se traduziu no crescimento significativo de suas empresas.

\title{
FEMALE ENTREPRENEURSHIP: A PHENOMENOLOGICAL STUDY
}

\begin{abstract}
The increase in the number of women entrepreneurs in various fields of business, changes in their role in society and their achievements were the factors that guided the development of this work. It aims to present the profile of the interviewed entrepreneurs, their personal characteristics, the development of their enterprises, as well as their current and future vision on their respective businesses. The research was developed based on the phenomenological-interpretive method, which proved adequate to identify not only the explicit characteristics of respondents, but also the subjective charcteristics of the interviewees, which demonstrate their entrepreneurial profile. The results showed that characteristics such as persistence, search for opportunities, initiative, commitment, persuasion and self-confidence which define a woman entrepreneur, were part of the interviewees psychological features.
\end{abstract}

Keywords: Female entrepreneurship. Phenomenological analysis. Entrepreneurial profile.

\section{REFERÊNCIAS}

COOLEY, L. Entrepreneurship training and the strengthening of entrepreneurial performance. Washington: USAID, 1990.

DICKSON, A. Mulheres no trabalho. Porto Alegre: Globo, 2010.

EVERS, Hand-Dieter. Towards a Malaysian Knowledge Society. In: International Malaysian Studies Conference, 3., 2001, Bangi. Proceedings... Bangi: Universiti Kebangsaan Malaysia, 2001. p. 1-23.

GLOBAL ENTREPENEURSHIP MONITOR. Empreendedorismo no Brasil. Curitiba: IBQP, 2012.

Disponível em: <http://www.gemconsortium.org/docs/download/2806>. Acesso em: 22 ago. 2013.

GOMES, A. F. Mulheres Empreendedoras. Vitória da Conquista: UESB, 2006.

LAPOLLI, E.; FRANZONI, A. M. Vitrine de Talentos. Florianópolis: Pandion, 2012.

ROSA, S. B.; SOUZA, V. A. B.; LOCH, A. Comportamentos empreendedores: por que as mulheres empreendem? In: LAPOLLI, E. M.; FRANZONI, A. M. B.;FELICIANO, A. M. (Org.). Mulheres em ação: notáveis empreendedoras em Santa Catarina. Florianópolis: Pandion, 2011. p. 20-41.

SCHUMPETER, J. A. Teoria do desenvolvimento econômico: uma investigação sobre lucros, capital, crédito, juro e ciclo econômico. São Paulo: Nova Cultural, 1997.

SEBRAE. Relatório de Negócios. Belo Horizonte : Sebrae, 2011.

TAYLOR, S.J.; BOGDAN, R. Introduction to qualitative research methods: a guidebook and resource. New York: J. Wiley, 1997.

ZAMPIER, M. A.; TAKAHASHI, A. R. W. Competências empreendedoras e processo de aprendizagem empreendedora: modelo conceitual de pesquisa. Cadernos EBAPE BR, Rio de Janeiro, v. 9, número especial, p. 564-585, jul. 2011. Disponível em: <http://www.scielo.br>. Acesso em: 14 mar. 2014. 